\title{
High Level Expression and Purification of Atl, the Major Autolytic Protein of Staphylococcus aureus
}

\author{
Vineet K. Singh \\ Microbiology and Immunology, Kirksville College of Osteopathic Medicine, A.T. Still University of Health Sciences, \\ 800 West Jefferson Street, Kirksville, MO 63501, USA
}

Correspondence should be addressed to Vineet K. Singh; vsingh@atsu.edu

Received 29 July 2013; Revised 16 September 2013; Accepted 24 October 2013; Published 19 January 2014

Academic Editor: Barbara H. Iglewski

Copyright (C) 2014 Vineet K. Singh. This is an open access article distributed under the Creative Commons Attribution License, which permits unrestricted use, distribution, and reproduction in any medium, provided the original work is properly cited.

Staphylococcus aureus is a major human and animal pathogen. Autolysins regulate the growth, turnover, cell lysis, biofilm formation, and the pathogenicity of $S$. aureus. Atl is the major autolysin in $S$. aureus. The biochemical and structural studies of staphylococcal Atl have been limited due to difficulty in cloning, high level overexpression, and purification of this protein. This study describes successful cloning, high level over-expression, and purification of two forms of fully functional Atl proteins. These pure proteins can be used to study the functional and structural properties of this important protein.

\section{Introduction}

Staphylococcus aureus is an aggressive pathogen that is responsible for a wide array of diseases from mild skin infections to life-threatening conditions such as bacteremia, pneumonia, and endocarditis [1-4]. The emergence of multidrug resistance in $S$. aureus is an enormous public health concern and there is an immediate need for additional and alternative therapeutic targets for infections caused by this bacterium [5].

Autolysins are enzymes that degrade the peptidoglycan cell wall layer and are called peptidoglycan hydrolases. They represent a diverse group of enzymes and appear to have redundant roles and more than one function [6, 7]. These enzymes include $\mathrm{N}$-acetylmuramidase, $\mathrm{N}$-acetyl glucosaminidase, $\mathrm{N}$-acetylmuramyl-L-alanine amidase, and endopeptidase [8-11]. While amidases break the bonds between the glycan strand and the stem peptides, the glycosidases are responsible for the cleavage of the glycan strands [7].

Cellular levels and activities of autolysins are believed to be intricately regulated and are proposed to play key roles in bacterial cell wall metabolism, daughter-cell separation, and antibiotic mediated cell lysis [2, 10]. Bacteria may secrete these autolysins and cause lysis of other bacteria that compete with S. aureus for nutrients [12]. The peptidoglycan hydrolases are important in bacterial pathogenicity $[13,14]$. These enzymes modulate muropeptide release which in turn activates host innate immune responses [13].

There is plenty of evidence to suggest that most $S$. aureus autolysins result from the processing of full-length Atl [9, 15]. The full length Atl is an $\sim 137 \mathrm{kDa}$ protein with two catalytically active domains [15-18]. A $63.3 \mathrm{kDa} \mathrm{N}$-terminal domain possesses amidase activity while a $53.6 \mathrm{kDa}$ Nterminal domain possesses the glucosaminidase activity [15$18]$.

Many investigators $[16,17,19]$ in the past have reported difficulty in cloning the full length $S$. aureus atl gene. A difficulty in overexpression in Escherichia coli has also hampered functional and structural studies with this important protein. Here we report the cloning of the full-length at gene in E. coli. Its expression was induced under appropriate conditions for large scale production of fully functional His-tagged Atl. The fully functional Atl protein was purified using a nickel affinity column and can facilitate structural and biochemical studies.

\section{Materials and Methods}

2.1. Bacterial Strains and Growth Conditions. E. coli strain JM109 (Promega) was used for all cloning experiments. In addition, E. coli strain BL21 (EMD Millipore) was used for 


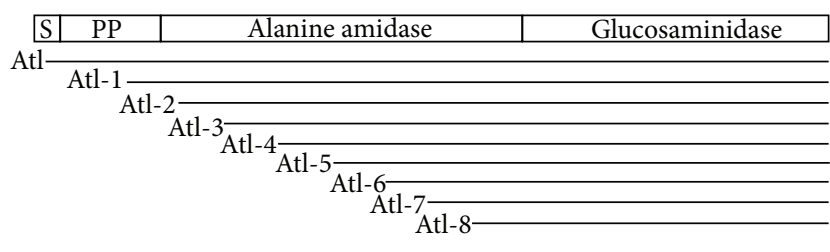

FIGURE 1: Diagrammatic representation of full-length staphylococcal atl and various shortened atl gene fragments that were cloned for overexpression in E. coli. The full length Atl $(\sim 137 \mathrm{kDa})$ possesses a signal peptide, a propeptide, and two catalytically active amidase and glucosaminidase domains.

all protein expression studies. Bacterial cultures were grown in Luria Bertani (LB) agar (Fisher) or in LB broth at $37^{\circ} \mathrm{C}$ in a static or shaking $(220 \mathrm{rpm})$ incubator. When required, ampicillin $\left(50 \mu \mathrm{g} \mathrm{mL}^{-1}\right)$ was added to the growth medium.

2.2. DNA Manipulations and Analysis. Plasmid DNA was isolated using the Qiaprep kit (Qiagen Inc.). Chromosomal DNA was isolated using a DNAZol kit (Molecular Research Center) from lysostaphin-treated $S$. aureus cells as per the manufacturer's instructions. All restriction and modification enzymes were purchased from Promega. EconoTaq DNA polymerase was purchased from Lucigen Corporation. DNA manipulations were performed using standard procedures. PCR was performed with the PTC-200 Peltier Thermal Cycler (MJ Research). Oligonucleotide primers were obtained from Eurofins MWG Operon.

2.3. Cloning of S. aureus atl Gene Fragments. The whole length atl gene and 8 additional atl gene fragments were PCR amplified using S. aureus RN450 [20] genomic DNA as the template. Nine forward primers and a common backward primer were used and are shown in Table 1. A BamHI site (underlined) was included in the forward primers to facilitate in frame subcloning. The full-length at gene amplicon included the entire coding region, the termination codon, and 10 additional downstream bases. The PCR amplicons representing the atl gene fragments lacked varying number of codons of the atl $5^{\prime}$-region as indicated in Table 1 in terms of the number of amino acids. These amplicons are shown diagrammatically in relation to the full length at gene in Figure 1. All amplicons were cloned in the pGEMT Easy Vector System (Promega). These atl gene and gene fragments were subsequently subcloned in frame at the BamHI and EcoRI sites of an overexpression vector pRSETA (Invitrogen). E. coli strain BL21 was subsequently transformed with the resulting nine plasmid constructs with atl gene fragments as described in Table 1.

2.4. Overexpression and Purification of Atl. The E. coli BL21 cells transformed with atl gene fragments in pRSETA were grown in LB broth containing ampicillin $\left(50 \mu \mathrm{g} \mathrm{mL}^{-1}\right)$ to an $\mathrm{OD}_{600}$ of 0.4 and induced for the synthesis of Histagged Atl proteins by the addition of $2.5 \mathrm{mM}$ isopropyl- $\beta$ thiogalactopyranoside (IPTG) for $2.5 \mathrm{~h}$. The induced bacterial cells were harvested and resuspended in $50 \mathrm{mM}$ Tris- $\mathrm{HCl}$ buffer ( $\mathrm{pH} 7.5)$ and sonicated. The sonicated extract was analyzed in $12.5 \%$ SDS-PAGE to check for over-expression of Atl.

Midexponential phase cultures of E. coli BL21 transformed with appropriate plasmid constructs were plated on LB agar plates with ampicillin $\left(50 \mu \mathrm{g} \mathrm{mL}^{-1}\right)$ for the purification of His-tagged full length Atl and truncated Atl proteins. After overnight incubation at $37^{\circ} \mathrm{C}$, the lawn of bacterial cells was recovered in $2.0 \mathrm{~mL} \mathrm{LB}$ broth and added to $500 \mathrm{~mL}$ of fresh LB broth with ampicillin. The induced bacterial cell cultures were grown to an $\mathrm{OD}_{600}$ of 0.4 and induced for the production of His-tagged Atl by the addition of $2.5 \mathrm{mM}$ IPTG for $2.5 \mathrm{~h}$. The induced cultures were harvested and sonicated in $5 \mathrm{mM}$ Tris- $\mathrm{HCl}(\mathrm{pH} 7.9)$ containing $500 \mathrm{mM} \mathrm{NaCl}$ and $5 \mathrm{mM}$ imidazole. The sonicated extract was centrifuged and the supernatant fluid was applied to a nickel-charged agarose affinity column (EMD Millipore) and eluted with $500 \mathrm{mM}$ imidazole in $5 \mathrm{mM}$ Tris- $\mathrm{HCl}$ ( $\mathrm{pH} 7.9$ ) containing $500 \mathrm{mM}$ $\mathrm{NaCl}$ after appropriate washes as recommended by the manufacturer. Fractions containing the overexpressed His-tagged Atl were pooled, dialyzed, and concentrated against $50 \mathrm{mM}$ Tri-HCl, pH 7.2. The dialyzed Atl proteins were assessed for purity and used for the detection of autolytic activity.

2.5. Determination of Lytic Activity of Atl Proteins. Lytic activities of different His-tagged Atl proteins were detected using a zymographic procedure as described previously [21, 22] using autoclaved $S$. aureus RN450 cells impregnated in $12.5 \%$ SDS-PAGE gels. The gels after electrophoresis were renatured for the autolysins by incubation in $50 \mathrm{mM}$ Tri- $\mathrm{HCl}$ buffer, pH 7.2, containing 0.05\% Triton X-100.

Lytic activities of purified His-tagged Atl proteins were also determined by measuring the loss of turbidity of a staphylococcal cell suspension. Autoclaved S. aureus RN450 cells were suspended in $50 \mathrm{mM}$ Tri- $\mathrm{HCl}$ buffer, $\mathrm{pH} 7.2$, containing $0.05 \%$ Triton $\mathrm{X}-100$ to an $\mathrm{OD}_{600}=1.0$. Purified Atl proteins $(50 \mu \mathrm{g})$ were added to $1.0 \mathrm{~mL}$ of the suspension and the decrease in turbidity $\left(\mathrm{OD}_{600}\right)$ after $1 \mathrm{~h}$ was measured spectrophotometrically.

\section{Results and Discussion}

3.1. Cloning, Overexpression, and Purification of Atl. Subsequent to PCR amplification, we successfully cloned and then sub-cloned the full length atl gene and eight truncated atl genes from the $5^{\prime}$-end in the vector pRSETA (Table 1). All these DNA fragments were downstream and in frame in pRSETA with a sequence that encoded an N-terminal fusion peptide of 34 amino acids. This peptide contained a polyhistidine tag as a metal binding domain that facilitated purification of the overexpressed recombinant Atl protein on a nickel affinity column.

E. coli strain BL21 was transformed with pRSETA plasmid containing atl gene or various atl gene fragments as shown in Table 1. The recombinant His-tagged Atl proteins were successfully overexpressed by the addition of IPTG to the mid-exponential phase cultures of appropriate transformants (Figure 2). It is evident that the full-length as well as all 


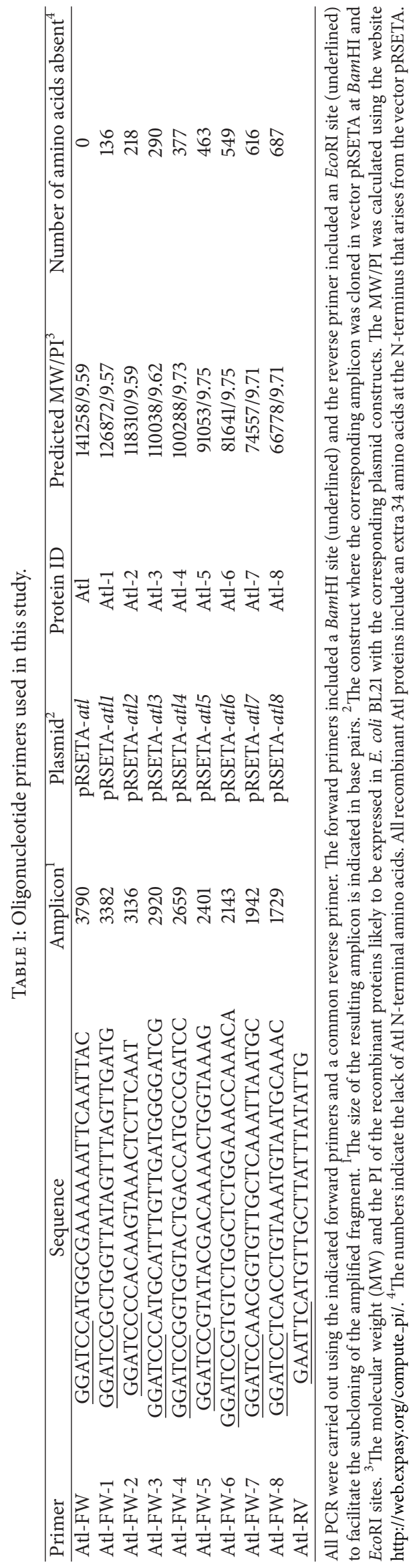




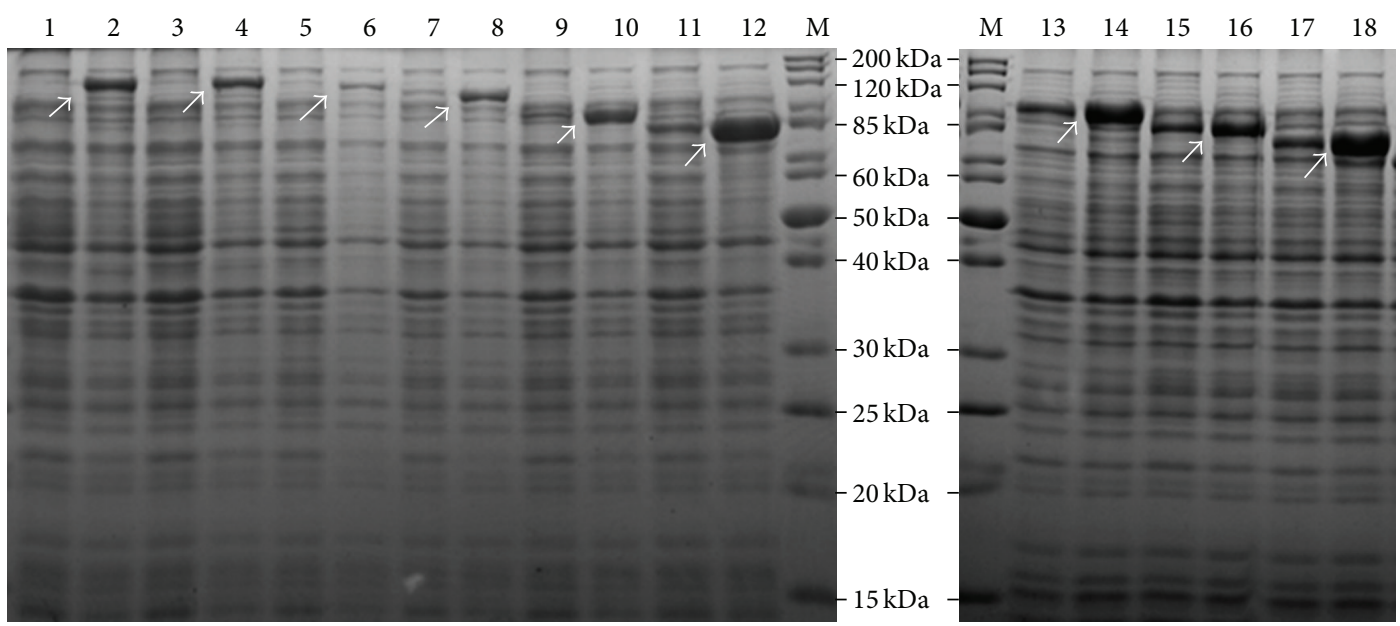

FIGURE 2: Coomassie stained gels demonstrating overexpression of recombinant Atl. The 12.5\% SDS-PAGE contains protein extracts of E. coli BL21 cells with pRSETA plasmids expressing either full length or truncated Atl proteins. The odd number labels are cells grown without IPTG and the even number labels are the cells grown with IPTG. Lane M: standard protein markers; lanes 1 and 2 - Atl (full length His-tagged Atl); lanes 3 and 4: Atl-1; lanes 5 and 6: Atl-2; lanes 7 and 8: Atl-3; lanes 9 and 10: Atl-4; lanes 11 and 12: Atl-6; lanes 13 and 14: Atl-5; lanes 15 and 16: Atl-7; lanes 17 and 18: Atl-8. The Atl number suffixes are indicated in Table 1.

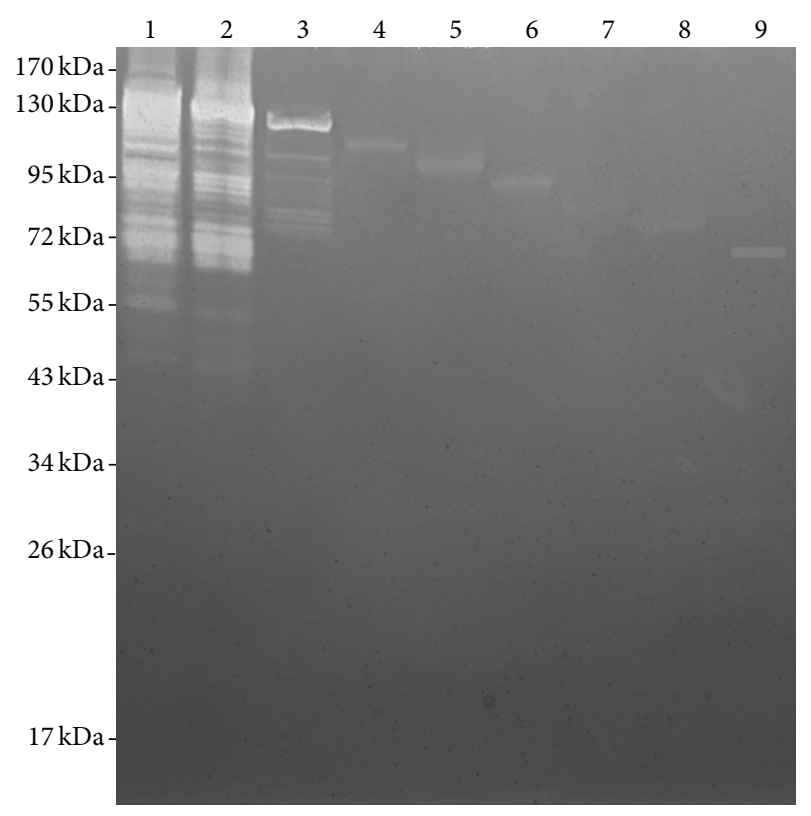

FIGURE 3: Zymographic detection of the autolytic activity in recombinant His-tagged Atl. Protein extracts from E. coli BL21 cells grown with IPTG were used in this study. The protein extract was separated by $12.5 \%$ SDS-gel electrophoresis. The SDS gel was impregnated with autoclaved $S$. aureus RN450 cells. Autolytic activity was detected by renaturing the autolysins by incubation of the gel in $50 \mathrm{mM} \mathrm{Tri-HCl}$ buffer, $\mathrm{pH} 7.5$, containing $0.05 \%$ Triton X-100. Lane 1: full length Histagged Atl; lane 2: Atl-1; lane 3: Atl-2; lane 4: Atl-3; lane 5: Atl-4; lane 6: Atl-5; lane 7: Atl-6; lane 8: Atl-7; lane 9: Atl-8.

truncated recombinant Atl proteins with the exception of Atl-2 (lane 6, Figure 2) were produced at a very high level in IPTG treated bacterial cells (short arrows, Figure 2). The apparent size of the overexpressed recombinant His-tagged Atl proteins matched closely with the predicted molecular weight of these proteins (Table 1 and Figure 2).
A zymographic technique was used to assess the autolytic activity of the recombinant Atl proteins. Autoclaved S. aureus RN450 cells were impregnated in the $12.5 \%$ SDS gel that was used to separate the E. coli cell extract containing the recombinant Atl proteins. When these SDS gels were renatured, the lanes representing the E. coli extract with full length Nterminal and C-terminal catalytic domains of Atl (Figure 3, Atl and Atl-1 in lanes 1 and 2, resp.) showed the highest activity with multiple lytic bands. The recombinant Atl proteins that possess only the $\mathrm{C}$-terminal glucosaminidase activity domain but truncated amidase domain did not result in any visible autolytic activity in the zymography (Figure 3, lanes 4-9). Truncated Atl proteins were produced at a very high level as can be seen in Figure 2 (lanes 8-18). In the zymography, the presence of these highly overexpressed proteins can be seen as a single dense band. There was no autolytic activity associated with these protein bands. Although Atl-2, with slight deletion of the N-terminal region of the amidase domain, demonstrated catalytic activity in the zymogram (Figure 3, lane 6), its expression level was low in $E$. coli BL21 cells under identical conditions that mimicked very high level expression of all other recombinant Atl proteins (Figure 2). This low level of Atl-2 may account for the limited lytic activity in the corresponding lane in the zymography (Figure 3, lane 3).

The purified recombinant His-tagged Atl proteins were also used to determine the lytic activity against staphylococcal cells. Consistent with the zymographic data, pronounced lytic activity was seen only with full length Atl and Atl1 and slight activity with Atl-2 (Table 2). No lytic activity was observed with any of the other recombinant His-tagged Atl proteins with larger deletions of the amidase domain (Table 2).

During overexpression of the recombinant His-tagged Atl proteins, IPTG was added to the E. coli BL21 cultures with appropriate plasmids at an $\mathrm{OD}_{600}=0.4$. In $2.5 \mathrm{~h}$ after 
TABLE 2: Lytic activity of purified recombinant His-tagged Atl proteins.

\begin{tabular}{lc}
\hline Protein & \% decrease in turbidity \\
\hline Atl & $56.76 \pm 2.09$ \\
Atl-1 & $50.69 \pm 5.50$ \\
Atl-2 & $5.73 \pm 0.32$ \\
Atl-3 & No decrease \\
Atl-4 & No decrease \\
Atl-5 & No decrease \\
Atl-6 & No decrease \\
Atl-7 & No decrease \\
Atl-8 & No decrease \\
\hline
\end{tabular}

${ }^{*}$ Average of three independent experiments \pm standard deviation.

the addition of IPTG, the final $\mathrm{OD}_{600}$ of these cultures was around 0.65 . We have used E. coli cells transformed with pRSETA with many cloned genes to overexpress various staphylococcal proteins for their characterization [11, 23-26] and, based on our previous experiences, we did not see any toxic effect of recombinant Atl on the E. coli BL21 cells. Using a nickel-charged agarose affinity column, we were able to successfully purify up to $4.0 \mathrm{mg}$ of recombinant Atl or Atl1 from a $500 \mathrm{~mL}$ IPTG-treated culture. Subsequent to nickel affinity column chromatography, the purity of recombinant Atl and Atl-1 was assessed by $12.5 \%$ SDS-PAGE. A single step column purification yielded reasonably pure forms of recombinant Atl and Atl-1 (Figure 4, lanes 3 \& 6, resp.). The autolytic activities of these pure recombinant Atl and Atl1 proteins were assessed using the zymographic technique. In zymographic analysis, the autolytic activity bands of recombinant Atl and Atl-1 ranged from $141 \mathrm{kDa}$ to $43 \mathrm{kDa}$ (Figures 3 and 5). The lytic bands resulting from recombinant Atl and Atl-1 can also be seen with respect to the lytic bands resulting from the total protein extract from $S$. aureus cells (Figure 3, lanes 1-5). Presence of multiple lytic bands associated with even pure Atl and Atl-1 supports the view that most $S$. aureus autolysins result from the processing of full length Atl $[9,15]$. The autolytic pattern of the purified recombinant Atl and Atl-1 that is similar to the crude E. coli extract containing these proteins (Figure 5, lanes $2 \& 3$, lanes $4 \& 5$ ) suggests that the processing of staphylococcal Atl is to a large extent an inherent process.

Many investigators have experienced problems in cloning and over-expression of full length staphylococcal Atl [16, 17, 19]. However, Hirschhausen et al. (2010) recently expressed full length Atl and different Atl-subdomains in E. coli [27]. Using these recombinant proteins, they were able to demonstrate that Atl mediates internalization of $S$. aureus cells by the nonprofessional phagocytic cells [27]. However, it is unclear what level of overexpression was obtained by Hirschhausen et al. [27].

Many roles have been proposed and shown experimentally for the staphylococcal Atl. It is postulated that Atl plays role in cell division $[9,15-17]$. By generating enzymatically inactive point mutations, it has been shown that both the amidase and the glucosaminidase domains of Atl must be

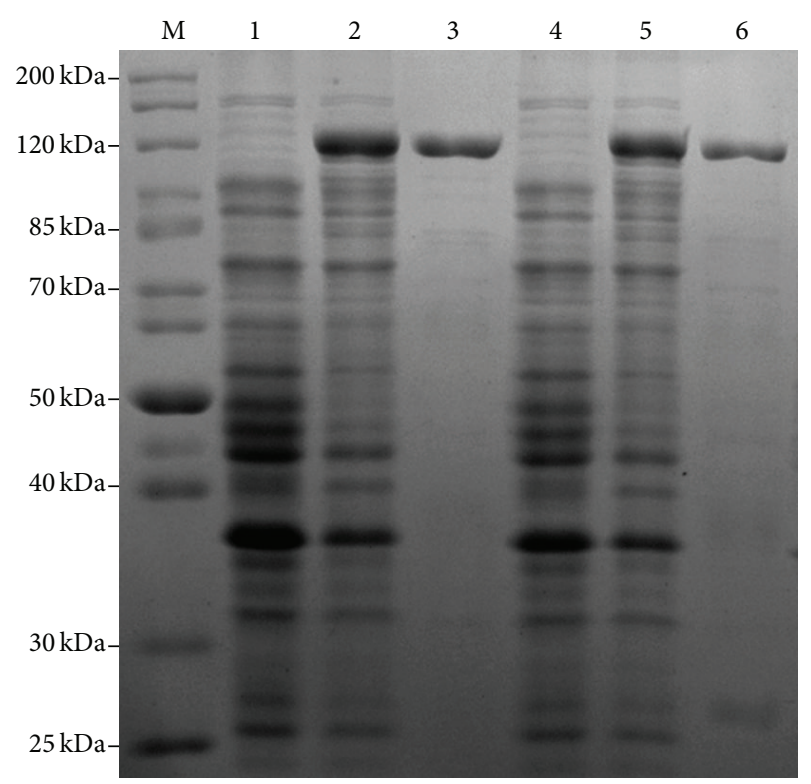

FIGURE 4: Coomassie stained gels showing purity of recombinant His-tagged Atl. Recombinant Atl and Atl-1 proteins were overproduced in E. coli and purified as described in the Materials and Methods section. Lane M: standard protein markers; lanes 1 and 2: protein extract from E. coli BL21 cells transformed with plasmids pRSETA-atl and grown without and with IPTG, respectively; lane 3: purified His-tagged Atl; lanes 4 and 5: protein extract from $E$. coli BL21 cells transformed with plasmids pRSETA-atl1 and grown without and with IPTG, respectively; lane 6: purified His-tagged Atl1 .

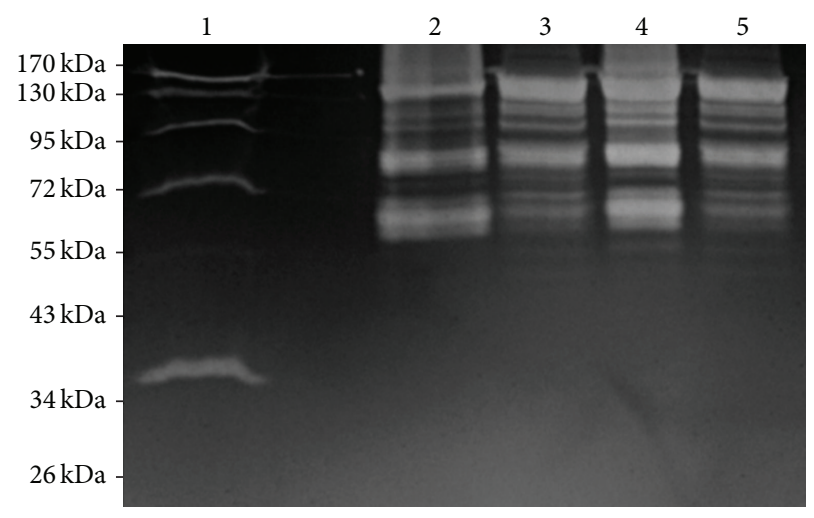

FIGURE 5: Zymographic detection of the autolytic activity in purified recombinant His-tagged Atl. Lane 1: total protein extract from $S$. aureus cells. Lanes 2 and 4: purified His-tagged Atl and Atl-1, respectively; lanes 3 and 5: protein extract from E. coli BL21 cells transformed with plasmids pRSETA-atl or pRSETA-atl1 and grown with IPTG, respectively.

catalytically active for S. aureus to form a biofilm [16]. Consistent with this finding, it has been shown that gallidermin, prevents biofilm formation by $S$. aureus. This lantibiotic also repressed the transcription of the gene encoding Atl [28]. Staphylococcal Atl is also reported to be involved in the excretion of cytoplasmic proteins. In a comparative analysis, many of the cytoplasmic proteins that are excreted by wild-type $S$. aureus cells, were significantly decreased in an atl mutant 
[29]. It has also been shown that atl mutants are significantly reduced in their capacities to be internalized by endothelial cells [27]. Atl mediated internalization of S. aureus cells by non-professional phagocytes may assist staphylococci in evading the host immune system [27]. Additionally, an autolysis-defective mutant showed reduced virulence in a rat endocarditis model, suggesting that autolysins are important for $S$. aureus pathogenicity [30].

In view of the ability of the autolysins to target the bacterial cell wall and regulate cell wall associated processes, the autolysins are being considered as effective antimicrobials with potentially important applications in medicine and biotechnology [31]. In addition, autolysins are also being targeted as potential vaccine candidates [32]. A detailed and insightful study with staphylococcal Atl has been limited thus far by the lack of the ability to make this protein in functional form and in large quantity. The plasmid constructs and the $E$. coli strains described in this study could be used to produce large amounts of functional Atl proteins that can be purified by one-step affinity chromatography. The purified Atl could then be used for more biochemical and structural studies and may lead to strategies to control infections caused by $S$. aureus.

\section{Conflict of Interests}

The author does not have any conflict of interests with the content of the paper.

\section{Acknowledgments}

The author thanks Dr. Neal R. Chamberlain for critical reading of this paper. This work was supported by a Grant 1R15AI090680-01 from the National Institutes of Health to Vineet K. Singh.

\section{References}

[1] K. Plata, A. E. Rosato, and G. Wegrzyn, "Staphylococcus aureus as an infectious agent: overview of biochemistry and molecular genetics of its pathogenicity," Acta Biochimica Polonica, vol. 56, no. 4, pp. 597-612, 2009.

[2] J. R. Mediavilla, L. Chen, B. Mathema, and B. N. Kreiswirth, "Global epidemiology of community-associated methicillin resistant Staphylococcus aureus (CA-MRSA)," Current Opinion in Microbiology, vol. 15, no. 5, pp. 588-595, 2012.

[3] E. Stenehjem and D. Rimland, "MRSA nasal colonization burden and risk of MRSA infection," The American Journal of Infection Control, vol. 41, no. 5, pp. 405-410, 2013.

[4] R. R. Watkins, M. Z. David, and R. A. Salata, "Current concepts on the virulence mechanisms of meticillin-resistant Staphylococcus aureus," Journal of Medical Microbiology, vol. 61, pp. 1179-1193, 2012.

[5] A. M. Rivera and H. W. Boucher, "Current concepts in antimicrobial therapy against select gram-positive organisms: methicillin-resistant Staphylococcus aureus, Penicillinresistant pneumococci, and vancomycin-resistant enterococci," Mayo Clinic Proceedings, vol. 86, no. 12, pp. 1230-1242, 2011.
[6] T. J. Smith, S. A. Blackman, and S. J. Foster, "Autolysins of Bacillus subtilis: multiple enzymes with multiple functions," Microbiology, vol. 146, no. 2, pp. 249-262, 2000.

[7] W. Vollmer, B. Joris, P. Charlier, and S. Foster, "Bacterial peptidoglycan (murein) hydrolases," FEMS Microbiology Reviews, vol. 32, no. 2, pp. 259-286, 2008.

[8] S. S. Ingavale, W. van Wamel, and A. L. Cheung, "Characterization of RAT, an autolysis regulator in Staphylococcus aureus," Molecular Microbiology, vol. 48, no. 6, pp. 1451-1466, 2003.

[9] L. Ramadurai and R. K. Jayaswal, "Molecular cloning, sequencing, and expression of lytM, a unique autolytic gene of Staphylococcus aureus," Journal of Bacteriology, vol. 179, no. 11, pp. 36253631, 1997.

[10] L. Ramadurai, K. J. Lockwood, M. J. Nadakavukaren, and R. K. Jayaswal, "Characterization of a chromosomally encoded glycylglycine endopeptidase of Staphylococcus aureus," Microbiology, vol. 145, no. 4, pp. 801-808, 1999.

[11] V. K. Singh, M. R. Carlos, and K. Singh, "Physiological significance of the peptidoglycan hydrolase, LytM, in Staphylococcus aureus," FEMS Microbiology Letters, vol. 311, no. 2, pp. 167-175, 2010.

[12] T. Uehara and T. G. Bernhardt, "More than just lysins: peptidoglycan hydrolases tailor the cell wall," Current Opinion in Microbiology, vol. 14, no. 6, pp. 698-703, 2011.

[13] J. Humann and L. L. Lenz, "Bacterial peptidoglycan-degrading enzymes and their impact on host muropeptide detection," Journal of Innate Immunity, vol. 1, no. 2, pp. 88-97, 2009.

[14] E. Scheurwater, C. W. Reid, and A. J. Clarke, "Lytic transglycosylases: bacterial space-making autolysins," International Journal of Biochemistry and Cell Biology, vol. 40, no. 4, pp. 586-591, 2008.

[15] S. J. Foster, "Molecular characterization and functional analysis of the major autolysin of Staphylococcus aureus 8325/4," Journal of Bacteriology, vol. 177, no. 19, pp. 5723-5725, 1995.

[16] J. L. Bose, M. K. Lehman, P. D. Fey, and K. W. Bayles, "Contribution of the Staphylococcus aureus Atl AM and GL murein hydrolase activities in cell division, autolysis, and biofilm formation," PLoS One, vol. 7, no. 7, Article ID e42244, 2012.

[17] T. Oshida, M. Sugai, H. Komatsuzawa, Y.-M. Hong, H. Suginaka, and A. Tomasz, "A Staphylococcus aureus autolysin that has an $\mathrm{N}$-acetylmuramoyl-L-alanine amidase domain and an endo- $\beta-\mathrm{N}$-acetylglucosaminidase domain: cloning, sequence analysis, and characterization," Proceedings of the National Academy of Sciences of the United States of America, vol. 92, no. 1, pp. 285-289, 1995.

[18] M. Sugai, H. Komatsuzawa, T. Akiyama et al., "Identification of endo- $\beta-\mathrm{N}$-acetylglucosaminidase and $\mathrm{N}$-acetylmuramyl-Lalanine amidase as cluster-dispersing enzymes in Staphylococcus aureus," Journal of Bacteriology, vol. 177, no. 6, pp. 1491-1496, 1995.

[19] C. Heilmann, M. Hussain, G. Peters, and F. Götz, "Evidence for autolysin-mediated primary attachment of Staphylococcus epidermidis to a polystyrene surface," Molecular Microbiology, vol. 24, no. 5, pp. 1013-1024, 1997.

[20] R. P. Novick, "Genetic systems in Staphylococci," Methods in Enzymology, vol. 204, pp. 587-636, 1991.

[21] V. K. Singh, D. S. Hattangady, E. S. Giotis et al., "Insertional inactivation of branched-chain $\alpha$-keto acid dehydrogenase in Staphylococcus aureus leads to decreased branched-chain membrane fatty acid content and increased susceptibility to certain 
stresses," Applied and Environmental Microbiology, vol. 74, no. 19, pp. 5882-5890, 2008.

[22] V. K. Singh, S. Utaida, L. S. Jackson, R. K. Jayaswal, B. J. Wilkinson, and N. R. Chamberlain, "Role for dnaK locus in tolerance of multiple stresses in Staphylococcus aureus," Microbiology, vol. 153, no. 9, pp. 3162-3173, 2007.

[23] J. Moskovitz, V. K. Singh, J. Requena, B. J. Wilkinson, R. K. Jayaswal, and E. R. Stadtman, "Purification and characterization of methionine sulfoxide reductases from mouse and Staphylococcus aureus and their substrate stereospecificity," Biochemical and Biophysical Research Communications, vol. 290, no. 1, pp. 62-65, 2002.

[24] V. K. Singh, J. Moskovitz, B. J. Wilkinson, and R. K. Jayaswal, "Molecular characterization of a chromosomal locus in Staphylococcus aureus that contributes to oxidative defence and is highly induced by the cell-wall-active antibiotic oxacillin," Microbiology, vol. 147, no. 11, pp. 3037-3045, 2001.

[25] V. K. Singh, A. Xiong, T. R. Usgaard et al., "ZntR is an autoregulatory protein and negatively regulates the chromosomal zinc resistance operon znt of Staphylococcus aureus," Molecular Microbiology, vol. 33, no. 1, pp. 200-207, 1999.

[26] A. Xiong, V. K. Singh, G. Cabrera, and R. K. Jayaswal, "Molecular characterization of the ferric-uptake regulator. Fur, from Staphylococcus aureus," Microbiology, vol. 146, no. 3, pp. 659668, 2000.

[27] N. Hirschhausen, T. Schlesier, M. A. Schmidt, F. Götz, G. Peters, and C. Heilmann, "A novel staphylococcal internalization mechanism involves the major autolysin Atl and heat shock cognate protein Hsc70 as host cell receptor," Cellular Microbiology, vol. 12, no. 12, pp. 1746-1764, 2010.

[28] J. Saising, L. Dube, A. K. Ziebandt, S. P. Voravuthikunchai, M. Nega, and F. Gotz, "Activity of Gallidermin on Staphylococcus aureus and Staphylococcus epidermidis biofilms," Antimicrob Agents Chemother, vol. 56, no. 11, pp. 5804-5810, 2012.

[29] L. Pasztor, A.-K. Ziebandt, M. Nega et al., "Staphylococcal major autolysin (Atl) is involved in excretion of cytoplasmic proteins," Journal of Biological Chemistry, vol. 285, no. 47, pp. 3679436803, 2010.

[30] N. Mani, L. M. Baddour, D. Q. Offutt, U. Vijaranakul, M. J. Nadakavukaren, and R. K. Jayaswal, "Autolysis-defective mutant of Staphylococcus aureus: pathological considerations, genetic mapping, and electron microscopic studies," Infection and Immunity, vol. 62, no. 4, pp. 1406-1409, 1994.

[31] J. A. Hermoso, J. L. García, and P. García, "Taking aim on bacterial pathogens: from phage therapy to enzybiotics," Current Opinion in Microbiology, vol. 10, no. 5, pp. 461-472, 2007.

[32] S. S. Tai, "Streptococcus pneumoniae protein vaccine candidates: properties, activities and animal studies," Critical Reviews in Microbiology, vol. 32, no. 3, pp. 139-153, 2006. 

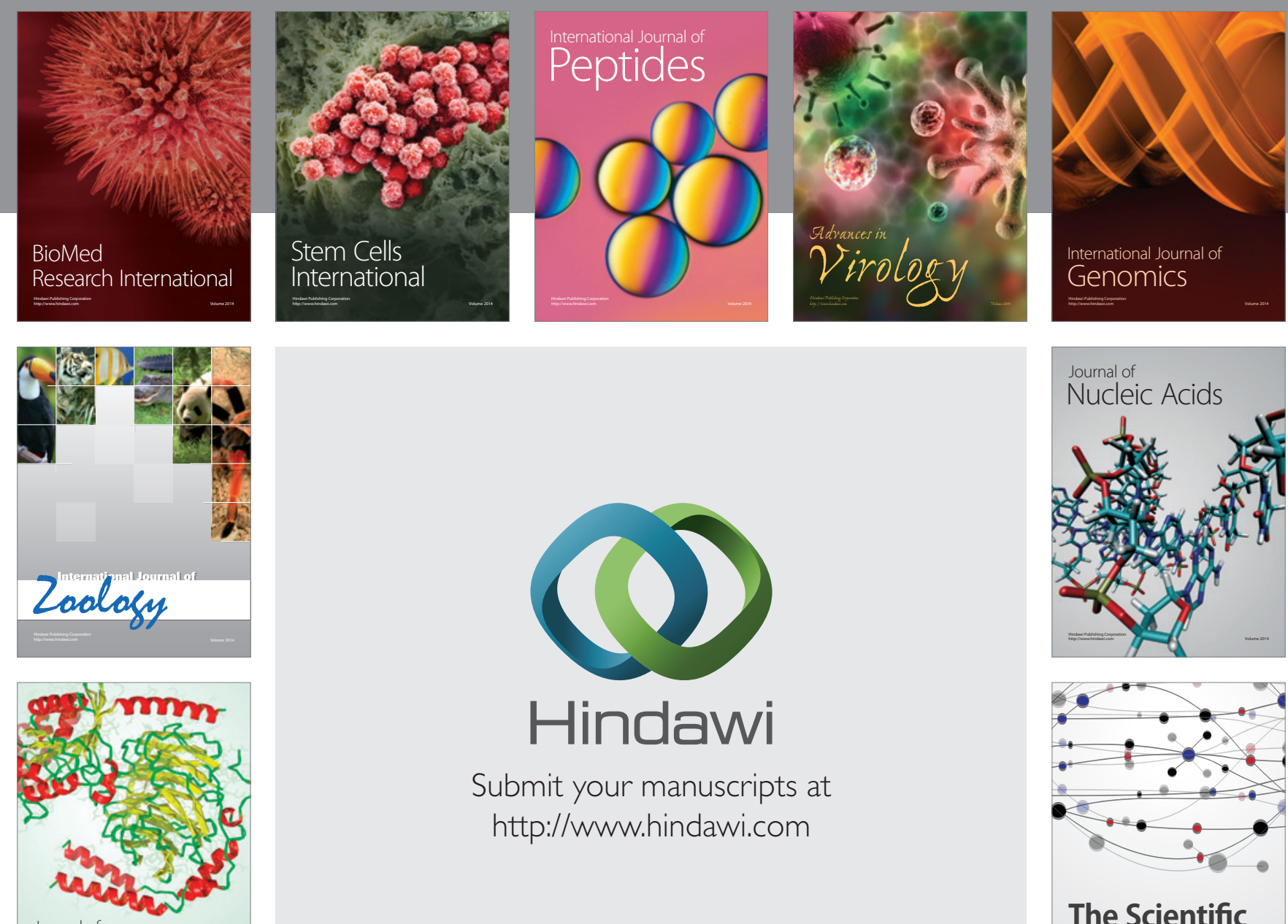

Submit your manuscripts at

http://www.hindawi.com

Journal of
Signal Transduction
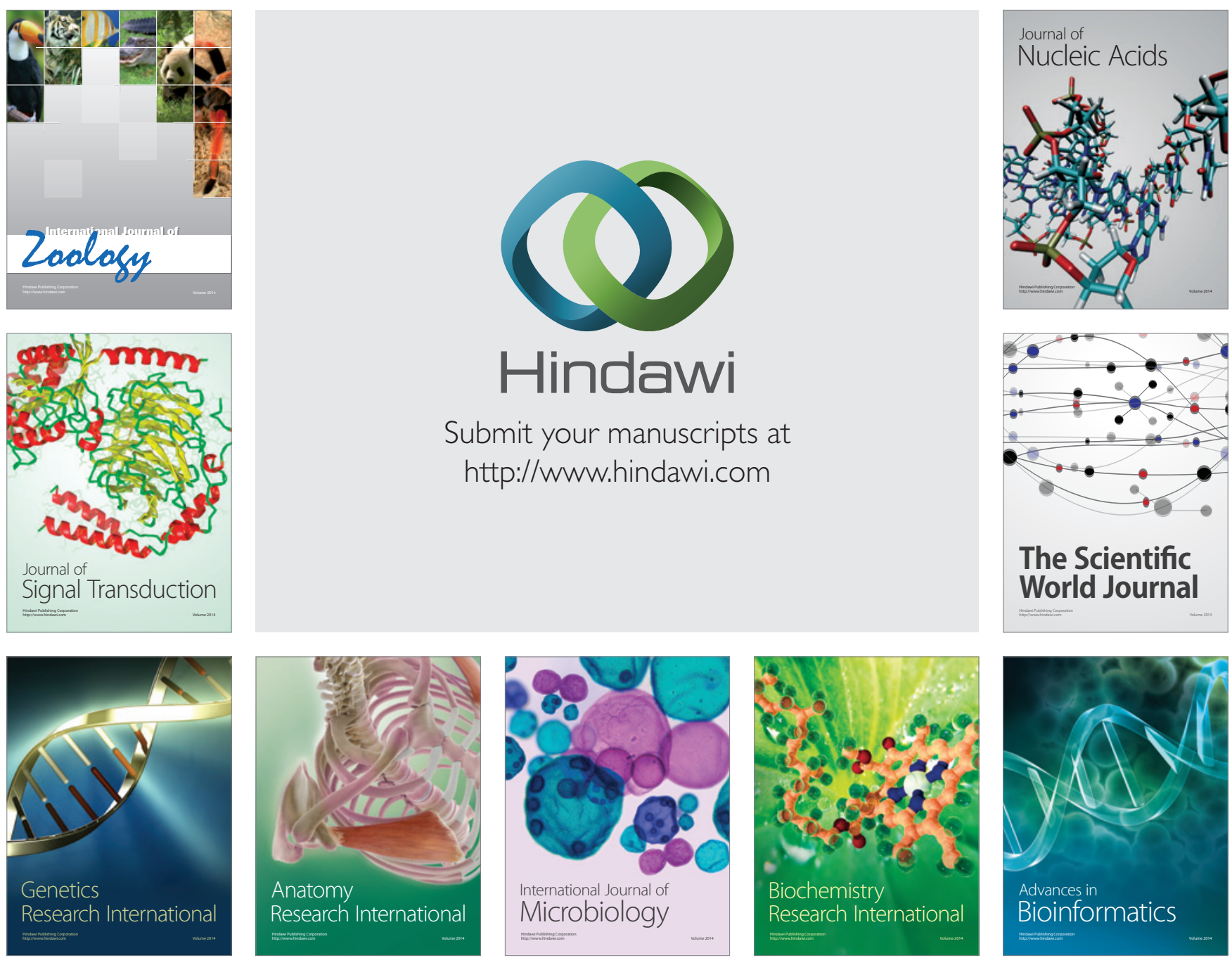

The Scientific World Journal
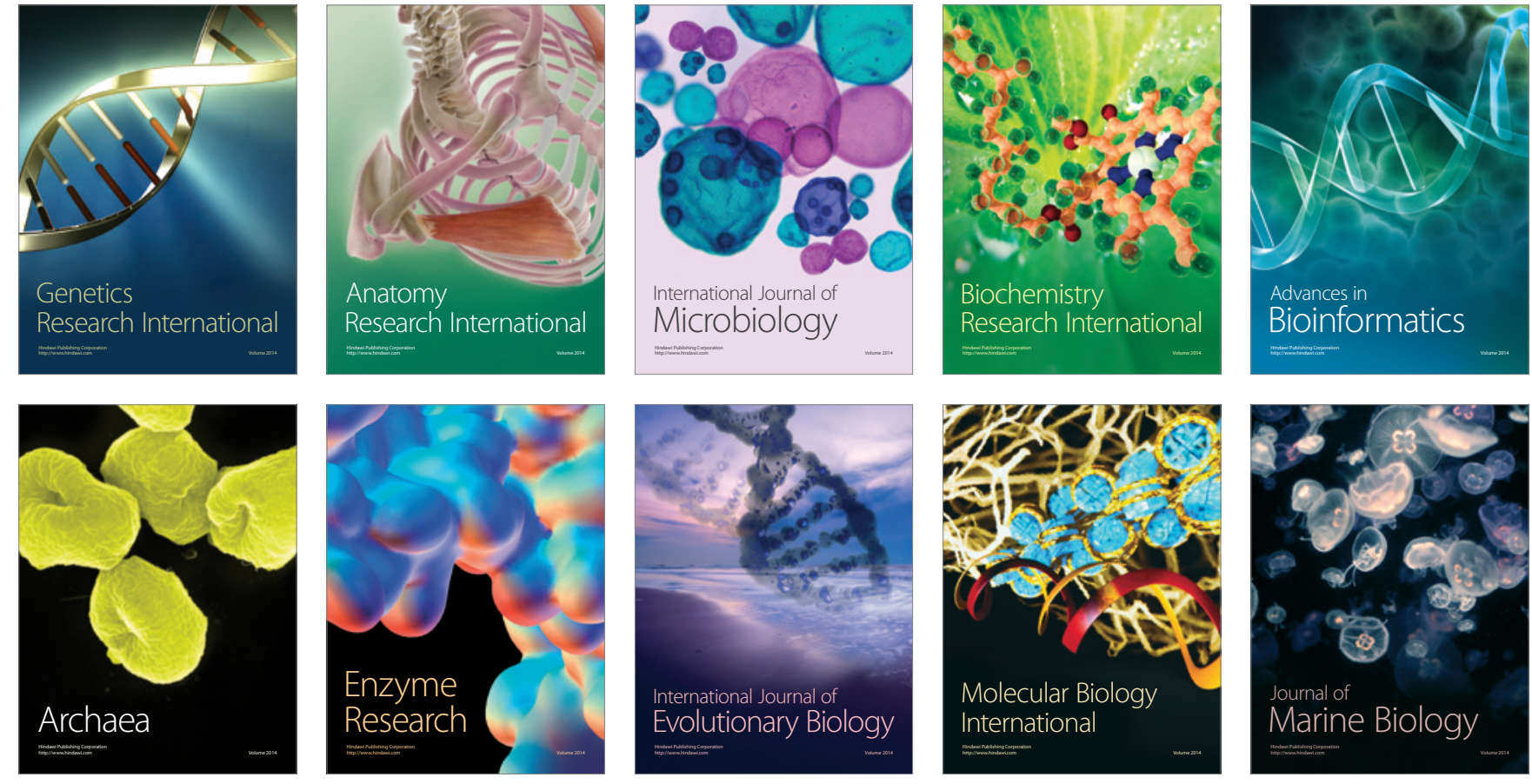